\title{
A manager's challenge: Is external supervision more valuable than increased training money for staff?
}

\author{
Craig Holz, Social Worker, New Zealand
}

\begin{abstract}
INTRODUCTION: Supervision is regarded as an integral necessity for the development and maintenance of professional standards in social workers and is also common practice in other health professions. There is debate, however, about the relative strengths of external and internal supervision. External supervision is recommended but there is a significant financial cost in contracting external supervisors. Also, some argue that internal supervision better manages staff and simplifies communication.
\end{abstract}

METHODS: This article provides a case study of an agency considering changing its supervision systems and the relative benefits and risks that need to be considered.

FINDINGS: Each agency needs to consider how to get the best from staff development resources considering the time or finances available. External supervision can offer wider choice to staff with more ethical issues debated. However, this may limit other staff development funding.

CONCLUSION: It is recommended that every agency regularly review how to get the best supervision for its staff.

KEYWORDS: Supervision; external supervision; internal supervision

Supervision is an expected element of social worker development and has been written about in New Zealand since the late 19th century (Kane, 2001). However, it is also a contested concept and there is an ongoing debate about the relative benefits of internal supervision by line managers as against external supervision. There is also debate about how supervision is best used to develop and nurture competent social workers in the challenges of today's social work environments.

This article will describe a fictional agency, its situation and the debate amongst its managers on whether changing from monthly external supervision to only internal supervision will better serve their workers and clients. It will also describe the research findings.

The agency, "Care and Support Trust," is a fictional agency based on characteristics of a number of agencies I am familiar with and the manager's quotes in the article are based on viewpoints from different managers in different agencies I have worked with.

\section{Care and Support Trust}

Care and Support Trust is a mental health, non-government organisation which contracts with the District Health Board, Accident Compensation Corporation, and
AOTEAROA

NEW ZEALAND SOCIAL WORK 31(3), 127-133.

CORRESPONDENCE TO: Craig Holz

csholz@orcon.net.nz 
the Ministry of Social Development. It employs 70 frontline staff and has a CEO, three managers and three administration staff. It provides respite services, residential services and community support workers providing follow-up to people living in the community as well as employment consultant services. Currently, the staff within the residential service take part in monthly group supervision. The managers and community support work staff and employment consultants receive external individual supervision monthly. The managers have regular coaching sessions either fortnightly or monthly with staff as needed where caseloads are reviewed and personal development matters discussed. The agency is developing the next year's budget and is reviewing the value for money of the current supervision arrangements.

\section{The current situation}

Care and Support Trust receives $\$ 700,000$ for its services. The expenses are broken down as follows:

\section{Table: Care and Support Trust Costs}

\begin{tabular}{|l|l|l|}
\hline \multicolumn{1}{|c|}{ Expense } & \multicolumn{1}{|c|}{ Cost } & \multicolumn{1}{c|}{ Percentage } \\
\hline Staff costs & $\$ 560,000$ & $80 \%$ \\
\hline Supervision & $\$ 35,000$ & $5 \%$ \\
\hline Vehicles & $\$ 21000$ & $3 \%$ \\
\hline Rent & $\$ 16,100$ & $2.3 \%$ \\
\hline Kiwisaver & $\$ 10,990$ & $1.57 \%$ \\
\hline Depreciation & $\$ 9,800$ & $1.4 \%$ \\
\hline EAP & $\$ 7,000$ & $1 \%$ \\
\hline IT & $\$ 7,000$ & $1 \%$ \\
\hline Phones & $\$ 3,920$ & $0.56 \%$ \\
\hline Training / & $\$ 3,500$ & $0.5 \%$ \\
Development & & \\
\hline Rates & $\$ 1,190$ & $0.17 \%$ \\
\hline Miscellaneous & $\$ 20,500$ & $2.93 \%$ \\
\hline Surplus & $\$ 4000$ & $0.57 \%$ \\
\hline
\end{tabular}

Managers are paid by salary and average 44 hours of work per week. To improve their financial viability, Care and Support Trust has removed two middle managers.
This means that now each manager oversees a team comprising of its health professionals, Monday to Friday community support workers, peer support workers, medication support staff rostered 7 days a week and employment consultants. The aim of this is to provide an integrated approach to the varied clients' needs and means that managers are now working to the requirements of several different contracts and reporting systems, making their job more complex.

\section{Management}

The managers at Care and Support Trust are Bob Harvey, Sue Naughton and Mary Heke (all composites for illustrative purposes, not real people).

Manager Bob Harvey is a nurse with 15 years' experience working in mental health in the United Kingdom and New Zealand. He values providing care according to people's needs and the ability to alter the support arrangements so that people are offered flexible ranges of support unique to them. Bob uses his wide experience to relate stories of how he has seen this before and what worked. Staff leave sessions learning a lot from him and with clear expectations of what he wants to happen to resolve the issues presented.

Manager Sue Naughton is an experienced manager. She follows protocols and used to manage a rest home. Sue ensures people are following policies and works hard on understanding and explaining policies. Sue would like further training on coaching. She values people demonstrating initiative and compliance to policy and believes in quality management.

Manager Mary Heke is a registered social worker who follows the ANZASW supervision policy guidelines in her coaching. However, this means that extra one-to-one coaching is needed for mentoring and following up on organisational requirements. Mary wants increased staff training options and also wants to have 
senior staff doing some of the coaching and mentoring. This would involve either developing the training herself which would involve 25 hours' work at an internal cost of $\$ 937.50$, or sending staff to a day's training with a well-established centre at \$495 + GST per person.

\section{The proposal}

The CEO John Naughton is looking for a financial solution that enables more choice and flexibility. The budget commits $95 \%$ of their funding and if unexpected costs occur then they can spend more than they receive, which happened last year for three months. In addition, the organisation has agreed with the union to provide employment assistance to staff and this will be an added cost. Staff currently get eight external supervision sessions per year at an average cost of $\$ 125$ per session and an annual cost per person of $\$ 1,000$.

Naughton has proposed removing external supervision except for health professionals and managers. This will reduce the number of staff getting external supervision by 28 and save $\$ 28,000$. It will double the training and development budget and create a financial cushion of $\$ 28,500$ giving increased flexibility for any unexpected costs.

A total of 35 of the staff are in the community services get one-to-one supervision; seven of these are health professionals. The annual costs for supervision average $\$ 1,000$ per staff member plus mileage for travel at $\$ 21.90$ plus the time cost of an average one hour's travel. The CEO's proposal to restrict supervision to health professionals would reduce the costs by $\$ 4,785.20$ per month and $\$ 672$ worth of staff time, however, it will increase the pressure on the managers' time.

In place of external supervision, staff will receive a monthly session devoted to what they want to discuss without any focus on organisation goals or performance management. The managers have already received supervision training as part of their professional development and will undergo a day's training on providing superviseeled supervision. This will cost the Care and Support Trust $\$ 1,500$ plus GST but will require extra coaching time for some staff monthly. This is estimated to cost $\$ 150$ in time monthly for the four staff per manager expected to need extra support.

\section{Supervision in the literature}

This section will outline the definition and focus of supervisions and what social workers look for in supervision. It will then move to the outcomes of supervision and the reasons it is promoted in the mental health sector.

Supervision is an interactive professional relationship and reflective process that focuses on the supervisee's practice, professional development and wellbeing with the objectives of improving, developing, supporting and providing safety for the practitioner and their social work practice. (O'Donoghue, 2010, p. 346)

Supervision is mainly provided one to one. This can be with the line manager (internal supervision) or with another member of the organisation or from outside the organisation (external supervision). Supervision can also be provided in group format and occur as a peer-support arrangement. The focus of supervision is supportive, educational and administrative and mediational. Hughes and Pengelly (1997) saw supervision as focusing on self-development, the workers' learnings re their caseload and their organisational requirements.

Social workers' perceptions of supervision were researched by O'Donoghue, Munford, and Trlin (2006), who found that having a choice in supervisors was highly regarded as well as a supportive relationship with trust, honesty and openness. Participants emphasised it was important to regularly have a safe space and time to discuss matters that were important to the social worker. They valued a person with the ability to 
develop a positive relationship and good knowledge and experience in their work. They also valued a style enabling them to learn and progress and that was interactive, supportive and empowering. They valued the accountability and safety this brought to their practice.

In recent years there has been some focus in the literature on the research evidence for supervision. Beddoe and Davys (2016) note that, although it is a reasonable assumption that supervision should improve staff practice, there is a lack of evidence linking supervision and improved consumer outcomes. In an important review of supervision research, Carpenter, Webb, and Bostock (2013) concluded that there was evidence that good supervision is associated with increased job satisfaction and retention of staff. Supervision is perceived to improve effectiveness of staff and there is some evidence that group supervision can increase critical thinking skills. It also improves workers' perceptions that they are being supported by their organisation.

The mental health workforce body Te Pou o te Whakaaro Nui (2013) developed a position paper on the role of supervision in the mental health and addiction workforce and noted that the benefits of professional supervision were promoting professional development, safe and ethical practice, staff wellbeing and improved outcomes for service users. Research by Sutcliffe (2007) noted that supportive supervision was linked to skill development and professional identity of mental health support workers.

\section{Internal supervision}

The social work literature identifies two main forms of supervision, internal and external. Internal supervision it can be linked to professional development and appraisal. In this article, one suggestion will be made on managing the tension between organisational requirements and professional development. Traditionally, only managers provided supervision to staff. This time was used to support the worker and teach them the skills for the role and the required organisational processes. The benefits of this mode are that the supervisor has access to information about their caseload and knows their skills and developments areas. The supervisor can also can see evidence of their work in the notes and reports and through participation in team meetings and case load reviews. This mode of supervision is easily linked to the performance appraisal process and any performance improvement plans, if necessary. Within the organisation it is easier to fully manage service delivery, facilitate professional development and focus practitioner work (Beddoe \& Davys, 2016). Rankine (2017) noted that internal supervision can be used to recreate and change team culture through exploring the assumptions behind staff actions and the organisation's policies and, if there are differences noted, whether they could be used to improve the client service.

Internal supervision does, however, tend to emphasise organisational policies and tends to focus on casework and organisational goals (Rankine, 2017). For this reason it can be useful to split the session between focusing on organisation requirements and using the supervision time to let the person explore possible options that would benefit clients most.

\section{External supervision}

The pros and cons of external supervision will be described. The merits of including external supervision amongst a range of supervision methods are highlighted. Beddoe (2011) links the sector shift towards external supervision with a need to be seen to manage risk. This could be related to a shift from practice development focused supervision to risk minimisation and monitoring particularly in the state sector. Additionally, in the New Zealand health sector since the 1990s, services have become increasingly multidisciplinary and the manager may well have a different professional training from their staff. 
Therefore, in that setting, the supervisor would often not be the line manager. Cooper (2006) found that line managers received little feedback from supervisors and supervision was not linked to the staff appraisal process. She found that supervision was a private arrangement sanctioned by the organisation and the focus was still on ensuring quality services to clients.

Beddoe and Davys (2016) note the potential benefits of external supervision as the freedom to choose the relationship, the opportunity to critically reflect and critique one's own practice and the policies of the organisation. Practitioners are more likely to raise ethical dilemmas when using external supervision.

Beddoe (2010) argues that one of the pitfalls of external supervision could be an unhealthy collusion between disgruntled staff and a supervisor who is unaware of the organisation's performance requirements. She also thought an external supervisor had an ambiguous mandate for dealing with poor performance and that the external supervision may deepen the gap between management and front line staff. Beddoe questioned whether this meant external supervision was, potentially, professionally damaging.

External supervision relies on reported performance rather than the 360-degree vision of line management and that it created the loss of a conduit for transfer of practice issues and knowledge back to the organisation (Beddoe \& Davys, 2016). Other disadvantages include the removal of supervision from site of practice, lack of accountably to organisational standards and policy and lack of organisational accountability for standards of supervision (Beddoe \& Davys, 2016). Supervisors may be unaware of organisation goals or values and how these are actioned. These issues could be addressed by communication between the three parties, manager, supervisor and supervisee (Morrell, 2001) and negotiated as part of the supervision contract. There can also be reports from external supervisors to line managers to address these issues. External supervision is not be considered enough on its own. Hirst (2001) recommended best practice as line management plus external supervision plus group or peer supervision.

Supervision is only one of a range of tools available to management. There is also appraisal, training, mentoring, coaching and line management direction. Organisation development is a way of combining staff and organisation and funder and clients' viewpoints (Hirst \& Lynch, 2004; Tsui, O’Donoghue, Boddy, \& Pak, 2017).

\section{The debate amongst the managers at Care and Support Trust}

Many of the points raised in the literature are illustrated in the debate among the managers of the fictional agency, Care and Support Trust, when they meet to discuss the proposal.

John advocates that "making this change this will give us more money for staff training if we recognise development needs and we will be able to fund two more to go to the Mental Health conference. It will put more pressure on us but staff will be travelling less and therefore have more client time." Bob agrees: "We will not be wasting money on people who are not learning from the supervision anyway. Some staff still do not know what to talk about at supervision and can't tell me what they learnt at external supervision. We need to keep supervision available to health professionals so they can meet registration criteria but it is a luxury to give it to all staff."

Sue, however, disagrees, "I give the best coaching that I can and I ensure staff achieve their KPIs but I don't have all the answers and sometimes it is useful for staff to talk to someone with a fresh viewpoint. Also, I cannot provide the cultural options that an external supervisor can offer." "That is true," agrees Mary, "and this change is going to create more pressure on us- although staff 
will have more time, we will be under extra pressure to fit in the extra supervision." Bob adds, "We can use the senior staff to do some coaching that will extend their skills and help us."

John raises the point that "Some staff were not using external supervision which was a risk for us and some we sent to external supervision to address issues and we didn't really know what the outcome of that was." Mary counters: "We can improve that by communicating with the supervisor. Good supervision can encourage a staff person to bring back the learning to us. We can ask what have they learnt and get feedback for our organisation."

"If we do this," Sue states, "I will need extra training in supervision." Mary adds, "Maybe we will have more focused supervision with staff to upskill them but that doesn't always mean they will be willing participants. If a person isn't going to productively take part then internal isn't any better than external. I worry we are creating a risk by removing people's choice. People change in their supervision needs as they develop and often need different supervision styles. I change my supervisor every two to four years so that I keep getting a fresh perspective. Staff will not be able to do this and will possibly become stale in their approach."

John finishes, "We need to come up with a solution that keeps us financially viable and enables us to promote staff wellbeing and develop their skills and practice."

Eventually they decide to continue with the current system. However, they also provide a day's training on providing supervision to their senior practitioners at a cost of $\$ 1,500$ plus GST. Supervision with the senior practitioners is then offered to staff as an alternative to external supervision with six staff taking up this offer and reducing supervision costs by $\$ 6,000$. Training is also developed for new staff on what to expect from supervision. Additionally, a plan is made to communicate to the supervisor if a staff member is placed on a performance improvement plan and request their feedback after three months as a backup for the support offered by the direct manager. They decide to review these processes again in a year.

\section{Conclusion}

This case study was created to demonstrate the debates that can occur in an agency when choosing the best supervision supports for staff. Organisations have to choose between the time costs of internal supervision or the financial cost of external supervision. External supervision is considered best practice in literature but are the financial costs worth the decreased training or staff resource costs it may defer? Internal supervision requires ongoing training and dedicated manager time to ensure supervision occurs. This subject is an ongoing debate amongst social service organisations.

How do you think an agency like the Care and Support Trust should measure their progress in a year's time? What would you recommend to such an agency in this situation to meet their need to provide the best service for the people they work with within the framework they have?

\section{References}

Beddoe, L. (2010). Surveillance or reflection: Professional supervision in "the risk society." British Journal of Social Work, 40(4), 1279-1296.

Beddoe, L. (2011). External supervision in social work: Power, space, risk, and the search for safety. Australian Social Work, 65(2), 197-213. doi:10.1080/031240 $7 \times .2011 .591187$

Beddoe, L., \& Davys, A. (2016). Challenges in professional supervision: Current themes and models for practice. London, UK: Jessica Kingsley.

Carpenter, J., Webb, C. W., \& Bostock, L. (2013). The surprisingly weak evidence base for supervision: Findings from a systematic review of research in child welfare practice (2002-2012). Children and Youth Service Review, 35, 1843-1853.

Cooper, L. (2006). Clinical supervision: Private arrangement or managed process? Social Work Review, 18(3), 21-30.

Hirst, V. (2001). Professional supervision for managers: An effective organisational development intervention-an 
inquiry based on the perceptions and experiences of managers of social work (Unpublished master's thesis). University of Auckland, Auckland, NZ.

Hirst, V., \& Lynch, A. (2005). External supervision - good or bad for the organisation? In L. Beddoe, J. Worrall, \& F. Howard (Eds.), Weaving together the strands of supervision: Proceedings of the 2004 (July) Conference, Auckland New Zealand (pp. 91-98). Auckland: Faculty of Education, University of Auckland.

Hughes, L., \& Pengelly, P. (1997). Staff supervision in a turbulent environment: Managing process and task in a front-line service. London, UK: Jessica Kingsley.

Kane, R. (2001). Supervision in New Zealand social work. In M. Connolly (Ed.), New Zealand social work contexts and practice (pp. 291-303). Auckland, NZ: Oxford University Press.

Morrell, M. (2001). External supervision-confidential or accountable? An exploration of the relationship between agency, supervisor and supervisee. Social Work Review, 13(1), 36-41.

O' Donoghue K. B. (2010). Towards the construction of social work supervision in Aotearoa New Zealand: A study of the perspectives of social work practitioners and supervisors (Unpublished doctoral dissertation). Massey University, Palmerston North, NZ.

O'Donoghue, K., Munford, R., \& Trlin, A. (2006). What's best about social work supervision according to association members? Social Work Review, 18(3), 79-91.

Rankine, M. (2017). Making the connections: A practice model for reflective supervision. Aotearoa New Zealand Social Work, 29(3), 66-78. doi:http://dx.doi. org/10.11157/anzswj-vol29iss3id377

Sutcliffe, R. (2007). What is the meaning of supervision for mental health support workers? A critical hermeneutic inquiry (Unpublished master's thesis). AUT University, Auckland, New Zealand.

Te Pou o te Whakaaro Nui. (2013). Position paper: The role of supervision in the mental health and addiction support workforce. Wellington, NZ: Author.

Tsui, M.S., O’Donoghue, K., Boddy, J., \& Pak, C.M. (2017) From supervision to organisational learning: A typology to integrate supervision, mentorship, consultation and coaching. The British Journal of Social Work, 47(8), 2406-2420. doi:10.1093/bjsw/bcx006 